Goldschmidt 2021 Abstract

https://doi.org/10.7185/gold2021.6682

\section{Triple magnesium isotope constraints on the origin of chondrules}

\author{
MARC CHAUSSIDON ${ }^{1}$, ZHENGBIN DENG ${ }^{2,3}$, DENTON S \\ EBEL $^{4,5}$, JOHAN VILLENEUVE ${ }^{6}$, JULIEN MOUREAU ${ }^{2}$ \\ AND FRÉDÉRIC MOYNIER ${ }^{7}$
}

${ }^{1}$ Université de Paris, Institut de physique du globe de Paris, CNRS UMS 3454

${ }^{2}$ Université de Paris, Institut de physique du globe de Paris, CNRS

${ }^{3}$ University of Copenhagen

${ }^{4}$ Department of Earth and Planetary Sciences, American

Museum of Natural History

${ }^{5}$ Department of Earth and Planetary Sciences, AMNH, NY

${ }^{6}$ Université de Lorraine, CNRS, CRPG

${ }^{7}$ Université de Paris, Institut de Physique du Globe de Paris, CNRS

Presenting Author: chaussidon@ipgp.fr

The question of the origin of chondrules is central in cosmochemistry: what is the inventory of chondrules' precursors, how were they processed during the chondrule forming events, what was the nature of these events and how did they control the mineralogical, chemical and isotopic composition of chondrules? Our approach was to develop an in situ nanosecond laser ablation multi-collector inductively-coupled-plasma mass-spectrometry (LA-MC-ICP-MS) technique to be able to measure simultaneously at high precision ${ }^{25} \mathrm{Mg} /{ }^{24} \mathrm{Mg},{ }^{26} \mathrm{Mg} /{ }^{24} \mathrm{Mg}$ and ${ }^{27} \mathrm{Al} /{ }^{24} \mathrm{Mg}$ ratios, giving access both to mass-dependent $\mathrm{Mg}$ isotopic fractionations $\left(\delta^{25} \mathrm{Mg}\right)$ and to radiogenic ${ }^{26} \mathrm{Mg}$ excess $\left(\delta^{26} \mathrm{Mg} *\right)$ in chondrules (Deng et al., GCA 2021). This technique allows to improve the measurement of $\mathrm{Mg}$ mass dependent isotopic variations in chondrules compared to secondary ion mass spectrometry (SIMS) because the magnitude of matrix effects on instrumental isotopic fractionation is reduced for LAMC-ICP-MS (1.0-1.5\%o/amu) compared to SIMS. We obtained 2 SD uncertainties of \pm 0.25 - $0.5 \%$ for $\delta^{25} \mathrm{Mg}$ values and of \pm 0.04 $0.60 \%$ for $\delta^{26} \mathrm{Mg}^{*}$ values, depending on the $\mathrm{Mg}$ content of the phase analysed in chondrules.

We studied 6 chondrules from the Allende and Leoville CV3 chondrites. The Mg-rich olivines in these chondrules show significant $\delta^{25} \mathrm{Mg}$ heterogeneities from $-1.22 \pm 0.24 \%$ o to $-0.05 \pm$ $0.24 \%$. For 3 out of 6 chondrules, the olivines show $\delta^{25} \mathrm{Mg}$ values which are identical within errors to those in the glassy mesostasis, clinopyroxene and plagioclase. However, for the 3 other chondrules the $\delta^{25} \mathrm{Mg}$ values are lower by $0.68-0.94 \%$ in olivines relative to the glassy mesostasis and other phases. The ${ }^{26} \mathrm{Al} /{ }^{27} \mathrm{Al}$ ratios calculated from the internal isochrons in these chondrules are similar to ratios previously found in chondrules from carbonaceous chondrites. The $\delta^{25} \mathrm{Mg}$ heterogeneities can be explained in a model where $\mathrm{Mg}$-rich precursor olivines partially dissolve in the chondrule melt undergoing $\mathrm{Mg}$ loss by evaporation. The different kinetics with temperature of olivine dissolution and $\mathrm{Mg}$ evaporation allow to constrain the timetemperature trajectory of chondrules which appear to be most consistent with a shock wave model. This model also allows to predict how the bulk $\delta^{26} \mathrm{Mg}^{*}$ values of chondrules will vary, just due to the temperature experienced by chondrules during their formation. 